\title{
Pós-graduação na ibero-américa. Conflito de temporalidades e embates. Tradição $x$ Modernidade
}

\section{Lucídio Bianchetti*}

\section{Resumo}

Pesquisa sobre a avaliação realizada pela CAPES, no Brasil, e a implementação do "Pacto de Bolonha", na União Europeia (UE), evidencia que esses dois são processos que se constituem em paradigmas de mudanças induzidas, aceleradas e em tempo exíguo. O desenvolvimento de pesquisa sobre a pós-graduação stricto sensu no Brasil e em algumas universidades da península ibérica coloca em relevo uma realidade similar, embora com defasagens temporais, dependendo do espaço onde estão processando-se as mudanças: a relação entre tradição e modernidade. É neste contexto que o antes, evocando tradição, e o agora, apontando (pós) modernidade, materializam-se em um tempo em que passado e presente se defrontam, muitas vezes na perspectiva da anulação de um passado, de uma tradição como se ipso facto fosse sinônimo de ultrapassado, de algo que tivesse que ser deixado para trás dado que não é mais operacional ao mercantilismo imperante no campo educacional. Nesta nova temporalidade, entre o "Modelos CAPES" e o "Processo de Bolonha", os intelectuais estão sendo desafiados a preservar um campo de praxis, onde a dialética entre tradição e modernidade não seja anulada, e eles, na condição de intelectuais públicos, reduzidos a intelectuais institucionalizados, cumpridores de funçôes, sem espaço para o exercício da autonomia. Neste texto, fruto de revisão para a pesquisa de pós-doutorado, apresento e analiso elementos básicos, do Estudo Comparado entre Brasil e UE.

Palavras-chave: Educação Tradicional e Moderna. Coordenação de Aperfeiçoamento de Pessoal de Nível Superior. Processo de Bolonha.

* Doutor em História e Filosofia da Educação (PUC/SP), com estágio pós-doutoral na Universidade do Porto/PT. Professor Associado da Universidade Federal de Santa Catarina (EED/CED). Pesquisador Produtividade $1 \mathrm{C}$ do CNPq. 


\section{Tradição e modernidade: um "território" convulsionado}

\section{Os conceitos em questão}

Modernidade e tradição são dois conceitos que geralmente aparecem relacionados de forma polar, dicotômica, maniqueísta, excludente. ${ }^{1}$ Metaforicamente são visualizados como flechas apontando para direções opostas. É como se um apontasse para o passado, para a valorização do que aconteceu, para a necessidade de conservação, e o outro indicasse a mudança, a transformação, para o constante movimento de busca de coetaneidade do e com o tempo presente, sempre tendo no horizonte o futuro em perspectiva. Chamar alguém ou um povo de tradicionalista pode ser percebido por alguns como elogio, uma vez que a essência do movimento ${ }^{2}$ é garantir que o passado não fique no passado e tudo se faça para presentificá-lo e perenizá-lo; para outros, a nominaçáo é apreendida como crítica, dado que aponta para a incapacidade de desligar-se, de desimpedir-se do passado, como se ele fosse um fardo, um peso a ser descartado.

A alcunha de moderno, de outra parte, reveste-se de um verniz, de uma coloração mais positiva, no sentido de que se refere a alguém, a um povo, país ou continente que, ao invés de fixar-se no já ido, com os pés firmes no presente, procura criar as bases para um outro espaço/ tempo, apostando no porvir. A palavra Tradiçáo, etimologicamente, remete à transmissão, ${ }^{3}$ fazendo da oralidade o meio por excelência de "entregar", geração, após geração, os segredos, as estratégias, os mitos criados, os ritos organizados e utilizados para a convivência e, no limite, à sobrevivência. Desde tempos imemoriais, pré-históricos, no domínio do campo da mitologia, nossos ancestrais encontraram formas, construíram estratégias para relacionar-se com os deuses, com seus semelhantes, indivíduos e grupos, com o meio circundante. Aquilo que garantiu a sobrevivência veio constituindo um patrimônio, uma herança, passada, entregue, transmitida de geração a geração. É neste contexto que vieram se forjando as crenças, as seitas, as religióes, os meios "instrucioeducacionais" e as formas hereditárias de governo. Com o tradicionalismo, como uma espécie de doutrina, busca-se a continuidade, a perenidade, a manutenção. E nesta perspectiva reveste-se da característica do conservadorismo. 
No mundo ocidental a tradição está profundamente arraigada à terra, ao nomadismo, ao gregarismo, à cidade-estado, ao feudo, à igrejauniversidade, à dependência do homem à natureza e à submissão daquele aos ditames e ritmos desta. A ritualização/repetição, o sucesso de governo estão associadas a essa cosmovisão.

Diferentemente, a modernidade está relacionada ao conceito de ruptura, de promessa, de construção do novo e de meio urbano. $\mathrm{O}$ nascimento da modernidade marca uma ruptura profunda com o medievo e, sem desconhecer o patrimônio do conjunto da humanidade (renascimento), particularmente a herança greco-romana, a ele não se aferra, pois a entronização do homem como centro, o antropocentrismo, destrona o teocentrismo, abrindo espaço para o "nascimento" do indivíduo e o seu protagonismo, tão bem sintetizado no movimento iluminista. Pesquisar, ter a coragem de descobrir, de sair da enclausuradora heteronomia é o desafio posto aos homens, como indivíduos e como coletivo, a partir da modernidade. Um desafio prenhe de possibilidades, especialmente se confrontado com o quanto o medievo significou de submissão, de fechamento, de encolhimento, de impedimento a qualquer atitude que pudesse confrontar os valores da tradição, nesse momento encarnados pela igreja e pela nobreza.

Se uma das principais características da tradição está associada a comportamentos, posicionamentos, modos de ser e viver, a questóes práticas e imediatas, dada a necessidade de sobrevivência nos limites do imediato, a modernidade passa a evidenciar-se em aspectos de posicionamentos também, mas sobretudo da separação homem-natureza, da interferência daquele sobre esta, dominando-a, transformando-a, colocando-a ao seu serviço. Além disso, desempenham papel fundante a forma de produzir o conhecimento, armazená-lo, transmiti-lo/apropriá-lo e colocá-lo em prática, via ciência e tecnologia, propiciando condiçóes de desembaraçar-se da ditadura da natureza, viabilizando a possibilidade de pensar, para além do imediato, a médio e longo prazo. Paralelamente, à religiáo passa a ser atribuído papel secundário, especialmente a partir da sua separação do Estado; a universidade - nascida das entranhas do medievo, profundamente vinculada à igreja e à nobreza - passa por uma revisão profunda na sua função transmissora e conservadora de um saber tradicional, universal, idealista, retórico. ${ }^{4}$ 
Na passagem do medievo para a modernidade, o saber, o conhecimento deixa de ser transmitido 5 e evocado para garantir o domínio sobre os outros, visando a conservação/transmissão - característica primordial da tradição e passa por uma quebra paradigmática, uma vez que, em termos de teoria do conhecimento, de inspiração/transmissão, passa-se à construção e aplicação, chegando no limite ao pragmático e utilitário. Contudo, seja na concepção tradicional ou moderna, a máxima baconiana do encontro entre conhecimento e poder, ${ }^{6}$ embora por caminhos e manifestaçóes diversas, permanece idêntica. Na perspectiva da tradição, o saber das pitonisas, dos arautos, dos xamãs, dos feiticeiros, dos filósofos, dos teólogos e daqueles para quem estes trabalhavam ou a quem se agregavam, granjeava poder, domínio. Na perspectiva da modernidade, a "sacralização" migra para os cientistas dos diversos campos do conhecimento, ${ }^{7}$ e o poder do seu saber passa a ser apropriado ou a beneficiar aos próprios e a quem os adota na condição de mecenas ou os contrata na condição de funcionários.

Sejam quais forem as circunstâncias, e assumindo a perspectiva marxiana, se a história da humanidade é a história da luta de classes; se a classe que está no poder tudo faz para manter-se - assumindo postura conservadora, tradicional - e a(s) que está(ão) alijada(s) tudo faz(em) para ascender ao poder - assumindo posição "moderna", "revolucionária" -, é com a assunção da burguesia, destronando um mix de heranças/tradições aristocráticas e da nobreza em conluio com a igreja, principalmente a partir do século XVI, que passamos a visualizar os contornos mais nítidos da modernidade da qual somos partícipes, beneficiando-nos e pagando o preço pelas promessas que não conheceram realização.

\section{Tradição e modernidade na ibero-américa}

A península ibérica assumiu o protagonismo de um determinado processo civilizatório na passagem da Idade Média para a Modernidade. A busca de novas terras d'além mar e a abertura de espaço para expansão do catolicismo, que vinha tendo seu "território e rebanho" reduzidos em terras europeias devido ao avanço da reforma protestante, entre outros aspectos, evidenciam que portugueses e espanhóis assumem a dianteira na era dos descobrimentos, no contexto de um entremesclamento de elementos do passado, do presente e do futuro, de tradição e de modernidade. E o preço 
que os dois reinos pagariam por esta postura ambígua, poderia dizer-se, não demoraria muitos séculos para ser cobrado/pago.

A descoberta do Novo Mundo garantiu essa expansão, essa vantagem competitiva em relação aos outros reinos da Europa e significou, em todos os sentidos, a afirmação da perspectiva eurocêntrica em termos de mundo ocidental. Para os ameríndios ${ }^{8}$ significou anexação, abandono compulsório de milenares tradiçóes, conhecimentos sistematizados e submissão - não sem resistência, mas esta insuficiente para travar ou redirecionar o processo civilizatório ibérico - ou extermínio, como ocorreu com o conjunto das civilizaçóes pré-colombianas. Entre as tradiçóes e os conhecimentos acumulados dos povos ameríndios e aquelas/es dos ibéricos, prevaleceram, melhor dizendo, foram impostas/os as/os destes.

A postura ambivalente a que fizemos referência relaciona-se ao fato de os ibéricos terem sido avançados no que diz respeito ao mercantilismo, abrindo-se para o futuro. Porém mantiveram-se fortemente arraigados às tradições em termos de forma de governo e forte submissão religiosa e educacional ${ }^{9}$ às orientaçóes/determinações papisto-romanas. E, de mais a mais, em termos de produção, de comércio, a dependência a importaçóes/ exportações ligadas aos setores extrativistas e a implementação da escravidão tardia, entre outros aspectos, levaram a que a península ibérica perdesse a vaga (onda) da entrada ou a adoção, juntamente com os outros reinos/países da Europa, do liberalismo em geral e do industrialismo, especificamente no que diz respeito ao mundo da produção. A perda desta vaga fez com que os ibéricos perdessem o protagonismo, de tal forma que até a compulsória transferência da família real lusitana para o Brasil, em 1808, fosse feita em função da imposição expansionista da França e sob a proteçáo interesseira da Inglaterra. De qualquer forma, a península ibérica perdeu o protagonismo da história tão perceptivelmente que, até há poucos anos, de forma mais explícita e mais recentemente de maneira menos aberta, ainda se ouviam ibéricos falando que iriam "viajar para a Europa", quando se dirigiam a outros países do chamado Velho Mundo.

Talvez um dos momentos por excelência no qual se fez uma inflexão nesse movimento de tentativa de Portugal ingressar efetivamente na vaga da modernidade tenha sido com Sebastião José de Carvalho e Melo (16991782), o Marquês de Pombal ${ }^{10}$. Sua adesão, nos limites do tempo e da sua posição, aos ideais do nascente liberalismo e principalmente do iluminismo, 
juntamente com a situação de desastres naturais e de enfraquecimento do poder expansionista e de apoio e proteção com que contou da parte do Rei José I, deram-lhe, por algum tempo, o poder de alinhar Portugal na trajetória da modernidade. A reconstrução de Lisboa - destroçada por um terremoto (maremoto?) -, a reforma política e econômica, a expulsão dos jesuítas, entre outras frentes e posturas assumidas, apontavam para um presente e futuro de Portugal em outra direção, direção que foi enfraquecida, senão vetada, com a assunção ao poder de Maria I, cujo reinado estendeu-se de 1777 a 1816.

Um segundo momento de inflexão nessa trajetória de Portugal em particular e da península ibérica em geral de alinhar-se com a modernidade foi a adesão ou a entrada de Portugal e Espanha na União Europeia, em 1986. No que diz respeito à educação, a adesão ao "Pacto de Bolonha" obriga o abandono de tradiçóes longevas, de características e peculiaridades de países e regióes e garante o alinhamento a uma modernidade cada vez mais submetida a questionamentos no sentido da realização do prometido, para o conjunto da população e para os diferentes países-membros da Uniâo Europeia.

\section{Temporalidades em conflito}

A questão do tempo é uma discussão central quando se analisam categorias como tradição e modernidade. $\mathrm{O}$ conflito, seja do ponto de vista pessoal, coletivo ou histórico, emerge quando a tridimensionalidade do tempo é colocada em xeque. Há dificuldades - compreensíveis! - de abandonar ideias, posicionamentos, posturas, espaços conquistados e que garantiram sobrevivência, confortos, vantagens. Não é comum e nem fácil aos seres humanos abrir mão das conquistas que custaram para sedimentarse e das quais auferiram vantagens.

Para abrir mão de uma vantagem certa - real ou suposta - em favor de uma vantagem em perspectiva, é preciso que indícios mínimos apontem para possibilidades iguais ou melhores na nova situação. Resistência a mudanças e adesão a possibilidades novas; tradição versus modernidade, terminam por instaurar um contencioso que acaba deixando defecçôes pelo caminho para alguns e acumulando favorecimentos para outros. De qualquer forma, não há como aderir ao novo sem que haja perdas. Porém, sem admitir essas perdas, não há como colocar-se na condição de beneficiar-se dos ganhos, 
que ao primeiro momento aparecem em potencial, deixando-se entrever nas brechas do conflito entre o que foi permanecendo e o que chega, sem ainda ter-se instituído. Compreender esta dialética não é algo que se dê sem luta, sofrimento, perdas e... ganhos. Compreender que tradição e modernidade se mesclam, se somam, se sobrepóem, se anulam, se reforçam não é algo imediatamente perceptível. É dos gênios do patrimônio cultural da humanidade que se apreendem liçôes de que "o passado é prólogo" ${ }^{12} \mathrm{e}$ que isto tem a ver com o conjunto da humanidade e não apenas com um indivíduo.

Contudo, quando se fala em aderir à modernidade, seria necessário que se fosse específico sobre o que significa esta adesão em termos de vantagens para o coletivo ou se a sua implementação ou adesão tem a ver com um discurso avançado travestido de modernidade, de avanço, porém materializando-se naquilo que há de mais negativo na tradição, no acontecido e que se pensava superado. Talvez a forma de deixar isto mais claro seja apresentarmos uma afirmação e um questionamento.

A afirmação refere-se ao comentário de Marx ([1982]), no livro O 18 Brumário de Luís Bonaparte, ao referir-se às possibilidades de o sobrinho (1808-1873) de Napoleão, com a experiência e o tempo, dar passos mais arrojados, mais avançados, na direção da modernidade:

A tradição de todas as gerações mortas oprime como um pesadelo o cérebro dos vivos. E justamente quando parecem empenhados em revolucionar-se a si e às coisas, em criar algo que jamais existiu, precisamente nesses períodos de crise revolucionária, os homens conjuram ansiosamente em seu auxílio os espíritos do passado, tomando-lhes emprestados os nomes, os gritos de guerra e as roupagens, a fim de apresentar a nova cena da história do mundo nesse disfarce tradicional e nessa linguagem emprestada. (MARX, [1982], p. 203).

Quanto ao questionamento, Giannetti (2002, p. 53), em uma das melhores e mais sintéticas manifestações sobre a tridimensionalidade do tempo, afirma que a modernidade prometeu, mas não entregou ou entregou menos do que prometeu, e conclui, perguntando: "Por que o amanhã feliz do ontem não se tornou o nosso presente?”. 
É neste contexto, entre atitudes e posturas que, ao invés de ancorar-se no presente e projetar-se adiante, apontam para um futuro que estaria em algum lugar do passado; entre promessas não ou parcialmente cumpridas, como é o caso da nova classe dominante, a burguesia, a partir do século XVII, em direção à hegemonia, que queremos situar a problemática da pós-graduação na ibero-américa, com foco especial na Coordenação de Aperfeiçoamento de Pessoal de Ensino Superior (CAPES), uma agência de controle e avaliação da pós-graduação (PG) do Ministério da Educação do Brasil e do Pacto ou Processo de Bolonha (PB), em especial no que diz respeito ao segundo e terceiro ciclos, este referente ao mestrado e ao doutorado.

E este último aspecto remete-nos à universidade e suas temporalidades, na relação conflituosa com outras temporalidades. Na citação de Paiva (1998, p. 125), este contencioso fica bem evidenciado:

O tempo da pesquisa é diferente do tempo da política. Em política, tudo é para ontem. O conhecimento, porém, precisa não apenas ser de hoje, mas ter caráter prospectivo. Em pesquisa, tudo é para amanhá. Não apenas por eventuais descomprometimentos com o mundo concreto e sua transformação, mas porque é preciso ócio e tempo para poder digerir adequadamente bibliografias e analisar dados concretos. Acrescente-se a isso o fato de que a maior parte dos pesquisadores, mesmo que tenham posiçóes políticas definidas ou engajamentos partidários, nunca passou por uma máquina estatal nem pela necessidade de administrar coisas e pessoas - com todos os seus supostos em matéria de compromissos, malabarismos para fugir aos impasses, enfrentamento com situaçôes sem solução que obrigam a criar novos problemas, adequação de medidas atuais a perspectivas de futuro que dificilmente poderão ser entendidas pelos atingidos, necessidade permanente de gerar novos fatos legitimadores etc. Quem está na máquina muitas vezes idealiza o mundo da pesquisa. Quem sai do mundo da pesquisa e entra na máquina política dificilmente retorna, não só porque sua perspectiva de tempo muda, mas também porque é 
verdadeiramente enorme o esforço necessário para reentrar numa vida mais reflexiva e crítica, bem como para colocar-se em dia com as leituras necessárias.

\section{Universidade, tradição e modernidade}

A universidade, com exceção da instituição eclesiástica, é a mais longeva instituição do mundo ocidental. Vão-se mais de 900 anos da criação da primeira: a universidade de Bolonha. E a instituição universidade surge e se mantém como instituição com características mais conservadoras, tradicionais do que como um espaço onde se cultiva a mudança. A maior inflexão paradigmática (KUHN, 1996) a que esta instituição vai ser submetida ocorrerá no século XIX, com a assunção de feiçôes mais localizadas, voltadas a realidades mais concretas, como foi o caso das matrizes humboldtiana (Alemanha), napoleônica (França) e newmaniana (Gran Bretanha), levando-a à perda da característica de Studium Generale (CAMBI, 1999) e de instituição supra-fronteiras. Nas palavras de Ribeiro (2007, p. 307), "as universidades sempre foram internacionalizadas, especialmente na Idade Média. Entretanto, no séc. XIX, houve uma fase nacionalista”. Embora dos primórdios até os séculos XVI e XVII a universidade fosse uma instituição de/para poucos, a ela acorriam estudantes e professores dos mais diversos reinos e países, em especial dos ocidentais, expondo-a a culturas diversas.

No que diz respeito à tradição no campo do ensino superior na relação da península ibérica com a América portuguesa e espanhola, vamos detectar que esta última passa a contar com universidades, já no século XVI (Peru, Santo Domingo e México), enquanto no Brasil, os primeiros cursos superiores vão ser criados com a chegada da Família Real, em 1808. No entanto, seja numa ou noutra das Américas, o fato de existirem cursos superiores desde o primeiro século da "descoberta" ou a partir de necessidades específicas da corte portuguesa, em nada modifica a condição de "não ser" da América Latina (ZIMERMANN, 1987) e do impedimento à busca de inserção na modernidade. A condição de colônia é pressuposto no que diz respeito àquilo que é permitido e possível transmitir, em termos de conhecimento e de posicionamentos. 
Nos séculos XIX e XX, a conservação e transmissão do saber, como uma das principais características da universidade, passará por profundos questionamentos frente à gradativa atribuição e assunção de funçóes de cunho mais pragmático e utilitário por parte desta instituição. Destacam-se aqui as constatações e críticas de Freitag (1996) e Chauí (2003), no que diz respeito à transformação da universidade da condição de instituição à de organização social e, especialmente o predomínio daquilo que Slaughter e Lesslie (1997) denominam de Academic Capitalism, com todas as consequências em termos de primazia do conhecimento aplicado e que garanta resultados, com a perspectiva do "managerialismo" (AMARAL; MAGALHÁES, 2003; SANTIAGO; MAGALHÁES; CARVALHO, 2005) que passa a predominar na sua forma de organização, gerenciamento e vinculação com o mercado. E no que diz respeito especificamente à pós-graduação, Silva Junior (2005) detecta aquilo que denomina de "racionalidade mercantil na pós-graduação", evidenciando com isto que todo sistema educacional, da graduação à PG, em termos de Brasil ou dos primeiro, segundo e terceiro ciclos, a partir do Processo de Bolonha, estão "atravessados" pelo espírito do tempo presente, com muito pouco interesse na tradição e com preocupaçóes de caráter pragmático e utilitário em relação ao hoje e ao futuro. A tradição aqui tornase um empecilho; a modernidade, por sua vez passa por uma releitura, a partir da qual os ideais do iluminismo são submetidos a um estreitamento e limitação de alcance.

\section{A CAPES e a pós-graduação (PG) no Brasil}

No início da década de 1950, são lançadas as bases para a criação de um sistema de PG no Brasil. Ligada ao Ministério da Educação, a "Campanha de Aperfeiçoamento de Pessoal de Nível Superior” (CAPES), na condição de "Campanha" é criada com o objetivo de "erradicar" o elevado número de professores que atuavam, sem condizente titulação, em universidades. Em 1949, foi discutida a proposta e, finalmente, em 1951, foi criado o Conselho Nacional de Desenvolvimento Científico e Tecnológico (CNPq) outro órgão governamental que ocupou e vem desempenhando papel fundamental na PG stricto sensu e na pesquisa e desenvolvimento tecnológico.

A criação desses dois órgãos deu-se no segundo governo de Getúlio Vargas (1950-1954), quando o país estava fazendo um grande esforço no 
sentido de entrar na era industrial, bem como, acreditavam os militares, o Brasil deveria desenvolver a energia atômica, de forma similar àquela feita por outros países. Quanto à CAPES, mais especificamente, as autoridades governamentais apostavam que a PG desempenharia papel chave no processo de estruturação e implementação de um programa de formação de professores, avaliação e fomento da pesquisa e da PG. Anísio Teixeira (19001971) foi secretário da CAPES durante os primeiros 15 anos de existência desta agência e, conforme Mendonça (2003), a aposta desse educador era a de que, por meio da PG, seria possível transformar a universidade brasileira.

Contudo, durante os primeiros 15 anos de existência da CAPES, que surge como "Campanha", essa se dedicou ao aperfeiçoamento de pessoal de nível superior e náo propriamente à PG no sentido stricto sensu como a entendemos hoje. Se pensarmos na PG Brasileira, como atualmente entendida, o sistema - que é formalizado apenas em 1965, com o parecer no 977/65 do CFE (CURY, 2005) - praticamente não funcionou, seja por falta de tradição no que diz respeito a uma proposta autóctone, seja pela "infância" da universidade brasileira, ${ }^{13}$ ou pela falta de recursos. Foi somente na década de 1970 que a proposta do sistema de PG foi resgatada e implementada, justamente em pleno regime ditatorial (1964-1985), sendo inserida no contexto do "Brasil Grande", projetado pelo governo militar. Foi então que se começaram a elaborar os Planos Nacionais de Pós-graduação e se passou a incentivar, melhor dizendo, a induzir, a criação de Associações Nacionais de Pós-graduação, ${ }^{14}$ por áreas de conhecimento, visando a contar com o suporte dos chamados pares para levar adiante a avaliação da PG.

$\mathrm{Na}$ área da educação, em particular, o primeiro Curso de PG foi organizado pela Pontificia Universidade Católica do Rio de Janeiro (PUCRio), no ano de 1965. E a criação deste curso e do próprio sistema brasileiro de PG foi organizado com base em distintos sistemas de PG, que, de acordo com Lüdke (2005), seriam o norte americano e o francês. Porém, as análises de Hamburguer (1980) e Sguissardi (2009) propiciam a compreensão de que a constituição do Sistema de Pós-graduação brasileiro é bem mais complexa do que a análise acima aponta.

Hoje, seja da perspectiva mais otimista, esposada por alguns analistas e principalmente pelos órgãos governamentais, o sistema é um sucesso. ${ }^{15}$ Afinal, financiar e avaliar a formação de 40 mil mestres e mais de $10 \mathrm{mil}$ doutores por ano é uma façanha de proporçóes respeitáveis se se tiver presente 
o pouco tempo de existência da PG no país. De outro lado, as críticas ${ }^{16}$ se avolumam por parte, principalmente de professores e pós-graduandos, com destaque para o produtivismo (SGUISSARDI; SILVA JUNIOR, 2009), a competição, a redução do tempo para a formação, o desrespeito a características e peculiaridades de áreas e de regióes, enfim, questóes que apontam para um conflito entre a busca da qualidade - apontado por críticos a esta postura como apego àquilo que há de mais tradicional na universidade - e a indução a uma posição mais atual, moderna da universidade, no sentido de vincular-se mais às necessidades do mercado.

Por fim, consideramos importante acrescentar também que, no momento em que a acreditação está em discussão, no contexto do Processo de Bolonha, na União Europeia (UE), a CAPES, como uma agência de avaliação e fomento (SGUISSARDI, 2009), vem avaliando a PG Brasileira por mais de 30 anos (RIBEIRO, 2007).

\section{O processo de Bolonha e a pós-graduação na UE}

Se a intenção das autoridades educacionais brasileiras era, via criação da PG, transformar a universidade, a palavra-chave nos documentos, nas declaraçóes e propostas que embasam o chamado "Pacto de Bolonha" ou também "Processo" ou ainda "Declaração", é reconstruçáo (KEELING, 2006). De um lado, é até compreensível a utilização deste verbo, se tivermos presente o tempo de existência de universidades no chamado Velho Mundo; de outro, porém, precisamos ter presente o quanto as pressóes em relação à perda do protagonismo, da competitividade da Europa está na base desse processo.

Convergem os autores no sentido de que os problemas colocados pela globalização (AMARAL; MAGALHAES, 2004; GIDDENS, 2007; BIRTWISTIE, 2009) estão na base dessa iniciativa que chega a provocar outros países e continentes a guiarem-se pela estratégia contida no denominado Processo de Bolonha (ADELMAN, 2008; ROBERTSON, 2009). E isto, particularmente no que diz respeito à criação de uma "área comum de educação superior", em um movimento que tem na base o "Processo de Bolonha", que cada vez mais se globaliza, conforme a última autora citada. 
Porém, aqui também, se, de um lado, há elogios à farta, de outro acumulam-se críticas, particularmente ao que diz respeito ao "ataque" à autonomia (AMARAL; MAGALHÁES, 2001) das universidades e ao desrespeito à diversidade cultural dos países membros da UE.

Diferentemente do que aconteceu no Brasil, onde um modelo único de PG foi imposto, na UE, qualquer decisão estava adstrita à decisão de cada Universidade. No entanto, sob Bolonha, particularmente através do Sistema Europeu de Transferência de Créditos (ECTS), visando a uma harmonização, uma standartização das universidades, podemos falar que a diversidade, as peculiaridades, as características, seja de países ou instituiçóes, passam a ser submetidas a um modelo único.

Tudo isto, com suas vantagens e problemas, coloca sob questionamento os conceitos de tradição e modernidade. Quais as decorrências de abandonar a tradição e assumir a modernidade no contexto do modelo CAPES e do Processo de Bolonha? Estas e outras tantas são questóes que estamos procurando responder por meio de pesquisa sobre a PG no Brasil e no contexto do Processo de Bolonha na União Europeia.

Seja qual for a situação, contudo, parece que estamos caminhando para uma perspectiva de convergência de modelos mais rapidamente do que gostaríamos e do que conseguimos perceber, começando pelo espaço ibero-americano. Note-se que, embora a proposta de um "Espaço Europeu de Educação Superior” (EEES) anteceda à Declaração de Bolonha, foi a partir da implementação desta que o EEES ganhou um forte impulso. E isto pode ser visto inclusive na perspctiva para além da União Européia. A declaração extraída como ponto culminante da Conferência Ibero-americana de Reitores e Responsáveis de Relaçóes Internacionais, realizada em fevereiro de 2004 na Universidade de Santiago de Compostela, na cidade homônima da Espanha, ficou conhecida como Declaração de Compostela (apud UNIVERSIDADE DE SANTIAGO DE COMPOSTELA, 2004). ${ }^{17}$ No processo de constituição do Espaço Europeu de Educação Superior, advindo dos múltiplos encontros que antecederam esta Conferência, destaca-se:

O espaço ibero-americano existe também como âmbito comum dotado de uma identidade própria que foi forjada através de um processo histórico, cultural 
e social, repleto de luzes e sombras, mas carregado de possibilidades abertas ao futuro. A construção de um espaço comum de educação superior neste âmbito constitui, antes de tudo, um bem social que se sustenta em valores compartilhados e se nutre deles, ao mesmo tempo em que reconhece a importância da educação e do progresso científico e tecnológico no desenvolvimento integral, eqüitativo e justo das nossas sociedades. A educação superior não é uma mercadoria, mas um bem público que contribui para a melhora da eqüidade e da qualidade de vida dos cidadáos, e a existência prévia de uma identidade ibero-americana deve servir como estímulo para reforçar a cooperação entre as instituiçôes de educação superior européias e latino-americanas visando atingir esse objetivo. (UNIVERSIDADE DE SANTIAGO DE COMPOSTELA, 2004, grifos nossos).

Em uma recente coletânea publicada no Brasil, Dias Sobrinho (2009, p. 131) afirma:

Se há nove séculos Bolonha concebeu a instituição que se espalhou primeiramente pelo ocidente e depois pelo mundo todo, no apagar das luzes do século XX, Bolonha inaugura um processo que pode vir a transformar consideravelmente a universidade na Europa e, em outras partes do mundo, como a América Latina.

Por fim, em uma coletânea que reúne as experiências mundiais sobre pós-graduação em Educação mais exitosas - incluindo o Modelo CAPES do Brasil -, em uma das conclusões, Nerad e Heggelund (2008, p. 312) reforçam que "all countries show some form of response to the Bologna process, the European Union's rapidly moving program of higher education reform”.

\section{Conclusão}

A grande questão que se coloca, do ponto de vista desta temática, é a respeito do que os dois modelos significam em termos de abandono de tradições e de assunçâo de elementos da chamada modernidade. 
De que tradiçóes estamos falando? Daquelas eivadas de obscurantismo que tanto impediram que se avançasse ou se olhasse em outras direçóes ou daquelas que forjaram historicamente pessoas, povos, naçóes e que compóem um peculiar patrimônio que está na base da formação da diversidade que enriquece o conjunto da humanidade?

De que modernidade estamos falando? Daquela que esteve na base de tantas promessas não cumpridas para o conjunto das populaçóes? Daquela que vincula o ser e o fazer da universidade aos ditames do mercado, fazendo prevalecer o ideal de somente ser valorizado aquilo que é prático e utilitário?

Se o velho ainda não foi e o novo ainda não se constituiu, como é possível trabalhar dicotomicamente os conceitos de tradição e modernidade? Como ou por que falar em pós-modernidade, se a modernidade ainda não se realizou?

Pensamos ser possível, particularmente com as contribuiçóes da pesquisa e da pós-graduação, resgatar ou reforçar a perspectiva dialética, um campo no qual tradição e modernidade se mesclam e se reforçam. Com isto será possível contribuir para que aquilo que foi decisivo para a sobrevivência (tradiçóes) e aquilo que garantiu ou pode garantir, para todos, uma vida melhor (modernidade), sejam resgatados e potencializados.

A chamada pós-modernidade - quando a modernidade ainda não se realizou na sua promessa -, a perda ou o enfraquecimento das metanarrativas demonstrou o quanto se está caminhando para uma perspectiva que não é do interesse do coletivo ou não preserva o coletivo. Depois de termos acompanhado a afirmação de uma American way of life and of doing science e de estarmos no processo de implementação de uma "Área Européia de Educação Superior", tudo indica que se desenha no horizonte uma "Área mundial de Educação Superior”. E nesta, parafraseando Gorges Orwel, no clássico Revolução dos Bichos: "todos são iguais, porém há alguns que são mais iguais do que os outros”.

\section{Notas}

1 Antecipamos que a forma dicotômica de análise que utilizamos é uma estratégia didática, de exposição/elaboração, uma vez que tradição e modernidade não podem ser apreendidas senão na perspectiva dialética de estreita vinculação e interdependência. 
2 Falamos em movimento uma vez que cada povo, cada etnia e, muitas vezes até uma localidade, uma nação ou um bloco, busca as melhores formas, utiliza as estratégias que considera mais adequadas para cultivar, manter suas tradições. Na Região Sul do Brasil, por exemplo, com muita força no Rio Grande do Sul, Oeste de Santa Catarina e Sul do Paraná e com forte presença em estados do Centro-Oeste e até do Norte e Nordeste, existem os Centros de Tradições Gaúchas (CTGs), cuja missão é preservar, cultivar as tradiçôes da pampa, região cuja fronteira foi móvel no decorrer de centenas de anos, desde a "descoberta" da América, dada a disputa entre ibéricos por extensas áreas de terra, principalmente do Sul do Brasil, e de partes da Argentina, do Uruguai e do Paraguai. De outra parte, no site Vida Radical (2011), argumenta-se sobre o quanto o povo português é afeito a tradiçóes, embora neste caso o destaque seja para aspectos religiosos.

3 Do Latim: traditio, tradere, no sentido de entrega.

4 Experiências, pesquisas, investigações práticas, nos limites do tempo, foram levadas a efeito em espaço diverso e em tempo anterior à criação da universidade, no início do segundo milênio. É o caso, por exemplo, do Museu de Alexandria, que poderia ser considerado o primeiro "instituto de pesquisa" da história do mundo ocidental (CAMBI, 1999).

5 Há aqui uma epistemologia com profundas raizes agostinianas, como o conhecimento "dando-se" por inspiração e transmissão, cuja sistematização mais qualificada se dá no século IV, com Santo Agostinho (354-430).

6 Referência ao Aforismo de Francis Bacon (1561-1626), segundo o qual, conhecimento e poder se "encontram" (BACON, 1999).

7 A menção aos diversos campos do conhecimento refere-se ao fato de até os teólogos estarem se submetendo a esquemas que em períodos anteriores à modernidade poderiam ser considerados heréticos, excessivamente mundanos. Apontamos aqui o fato de, no Brasil, até os cursos de pós-graduação em Teologia ou Ciências da Religião serem financiados e avaliados pela Agência estatal Coordenação de Aperfeiçoamento de Pessoal de Nível Superior (CAPES), órgão do Ministério da Educação (SOARES; PASSOS, 2008). 
8 Atemo-nos aqui à expansão lationamericana, sem deixar de ter presente que o processo foi similar em qualquer dos continentes nos quais os ibéricos ou outros "descobridores" estiverem presentes.

9 Uma das mais luminares manifestaçóes a este respeito pode ser visualizada pelo papel desempenhado pela Companhia (nominação coetânea ao tempo!) de Jesus. Os jesuitas tiveram sua "missão" prevista inicialmente por Inácio de Loyola (1491-1556) de "padres guerreiros" modificada por determinação pontifícia para "padres missionárioseducadores", tornando-se presença certa junto às expediçóes dos ibéricos a qualquer parte do mundo onde fossem ampliar as posses Del'Rei e arrebanhar almas para as "orbes celestiais".

10 Foi primeiro-ministro de José I, que reinou entre 1750-1777, monarca considerado um "esclarecido", um reformador.

11 "Pacto" assumido por reitores de universidades da União Europeia, na cidade de Bolonha, no ano de 1999, aludindo aos festejos dos 900 anos de criação da Universidade de Bolonha. Enfatizamos que a questão do mestrado e doutorado (segundo e terceiro ciclos) vai aparecer explicitamente apenas na Declaração de Berlim, no ano de 2003. Para maiores detalhes sobre o "Pacto" ou "Processo de Bolonha" em geral e no Brasil, em particular, ver: Robertson (2009); Dias Sobrinho (2009) e Bianchetti (2010).

12 Frase de um dos personagens de William Shakespeare (1564-1616), na peça "A tormenta" (1623).

13 Embora, como apontamos, os primeiros cursos superiores no Brasil tenham sido criados em 1808, diretamente vinculados às necessidades imediatas da corte Portuguesa (Direito, Cirurgia, Engenharia Naval e de Minérios etc.), foi somente a partir da década de 1920 que surgiram as primeiras universidades no Brasil, a partir da aglutinação de faculdades que foram criadas e funcionavam isoladamente nos anos anteriores. Destacam-se nesse pioneirismo as Universidades do Distrito Federal, de Minas Gerais e de São Paulo. Para aprofundamento cf. coletânea organizada por Mancebo e Fávero (2004).

14 Foi no bojo dessa indução que a Associação Nacional de Pós-graduação e Pesquisa em Educação foi criada em 1978. Para mais detalhes sobre 
a criação da ANPEd e das Associações Cientificas, Cf. Bianchetti (2009).

15 Cf., por exemplo Brasil (2010).

16 Dois números temáticos de reconhecidas Revistas da área de educação, reúnem o essencial dessas críticas. Cf. Revista Brasileira de Educação (2005) e a Perspectiva (2006). As principais críticas voltam-se aos efeitos que a vinculação fomento-avaliação provocam no sentido de descaracterizar a educação e a própria avaliação.

17 Do Brasil estiveram presentes nesse evento representantes de diversas Instituições de Educação Superior brasileiras, englobando todas as categorias administrativas públicas e privadas definidas nos artigos 19 e 20 da Lei no 9.394/96 (BRASIL, 1996).

\section{REFERÊNCIAS}

ADELMAN, C. The Bologna Club: what U.S. higher education can learn from a decade of European reconstruction. Washington, DC: Institute for Higher Education Policy, may, 2008. Disponível em: <www. ihep.org/Research/GlobalPerformance.cfm>.

AMARAL, A.; MAGALHÁES, A. Epidemiology and the Bologna saga. Kluwer Academic Publishers, Amsterdam, n. 48, p. 79-100, 2004.

AMARAL, A.; MAGALHÁES, A. The triple crisis of the university and its reinvention. Higher Education Policy, Paris, n. 16, p. 239-253, 2003.

AMARAL, A.; MAGALHÁES, A. On markets, autonomy and regulation the Janus Head Revisited. Higher Education Policy, Paris, n. 14, p. 7-20, 2001.

BACON, F. Os pensadores. São Paulo: Nova Abril, 1999.

BIANCHETTI, L. Os dilemas do coordenador de Programa de Pós-graduação: entre o burocrático-administrativo e o académicopedagógico. In: BIANCHETTI, L.; SGUISSARDI, V. (Org.). Dilemas da pós-graduação: gestão e avaliação. Campinas, SP: Autores Associados, 2009. 
BIANCHETTI, L. O Processo de Bolonha e a intensificação do trabalho na universidade. Entrevita com Josep M. Blanch. Educação \& Sociedade, Campinas, SP, v. 31, n. 110, p. 263-286, 2010.

BIRTWISTLE, T. Towards 2010 (and then beyond): the context of the Bologna Process. Policy \& Pratices, London, v. 16, n. 1, p. 55-63, 2009.

BRASIL. Coordenação de Aperfeiçoamento de Pessoal de Nivel Superior. Disponível em: <www.capes.gov.br/>. Acesso em: 10 fev. 2010.

BRASIL. Lei n. 9.394, de 20 de dezembro de 1996. Estabelece as diretrizes e bases da educação nacional. Diário Oficial da União, Brasília, p. 27833, 23 dez. 1996.

CAMBI, F. História da pedagoga. São Paulo: Ed. da UNESP, 1999.

CHAUÍ, M. A universidade pública sob nova perspectiva. Revista Brasileira de Educação: ANPEd, Rio de Janeiro, n. 24, p. 05-15, set/dez. 2003.

CURY, C. R. J. Quadragésimo ano do Parecer CFE n. 977/65. Revista Brasileira de Educação: ANPEd, Rio de Janeiro, n. 30, p. 7-22, set.-dez. 2005.

DIAS SOBRINHO, J. O Processo de Bolonha. In: PEREIRA, E. M. de A.; ALMEIDA, M. de L. P. (Org.). Universidade contemporânea: políticas do Processo de Bolonha. Campinas, SP: Mercado de Letras, 2009.

FREITAG, M. Le naufrage de l'université. Paris: Educations de la Découverte, 1996.

GIANNETTI, E. Felicidade: diálogos sobre o bem-estar na civilização. São Paulo: Companhia das Letras, 2002.

GIDDENS, A. A Europa na era global. Barcarena: Presença, 2007.

HAMBURGER E. Para que pós-graduação? In: ANDRADE, M. et al. Encontros com a civilização brasileira. Rio de Janeiro: Civilização Brasileira, 1980. p. 81-93.

KEELING, R. The Bologna Process and the Lisbon research agenda: the European Comission's expanding role in higher education discurse. European Journal of Education, Oxford, v. 41, n. 2, p. 203-223, 2006. 
KUHN, T. The structure of scientific revolutions. 3. ed. Chicago: The University of Chicago Press, 1996.

IANNI, O. A sociedade global. São Paulo: Brasiliense, 1992.

LÜDKE, M. Influências cruzadas na constituição e na expansão do sistema de pós-graduação stricto sensu em educação no Brasil. Revista Brasileira de Educação: ANPEd, Rio de Janeiro, n. 30, p. 117-123, set./ dez. 2005.

MANCEBO, D.; FÁVERO, M. de L. de A. Universidade: políticas, avaliação e trabalho docente. São Paulo: Cortez, 2004.

MARTINS, J. de S. A sociabilidade do homem simples: cotidiano e história na modernidade anômala. São Paulo: Contexto, 2008.

MARX, K. O 18 Brumário de Luís Bonaparte. In: MARX, K.; ENGELS, F. Obras Escolhidas. São Paulo: Alfa-Omega, [1982]. v. 1.

MENDONÇA, A. W. P. C. A pós-graduação como estratégia de reconstrução da universidade brasileira. Educar em Revista: Setor de Educação da UFPR, Curitiba, n. 21, p. 289-308, 2003.

NERAD, M.; HEGGELUND, M. (Ed.). Toward a global PhD? forces \& forms in doctoral education worldwide. Seattle: University of Washington Press, 2008.

PAIVA, V. Pesquisa educacional e decisão política. In: WARDE, M. J. (Org.). Novas politicas educacionais: críticas e perspectivas. São Paulo: PUC, 1998.

PERSPECTIVA. Florianópolis: NUP/UFSC, v. 24, n. 1, 2006.

Disponível em: <http://www.perspectiva.ufsc.br/>. Acesso em: $10 \mathrm{fev}$. 2010.

REVISTA BRASILEIRA DE EDUCAÇÃO: ANPEd. Rio de Janeiro, n. 30, 2005. Disponível em: <www.anped.org.br/rbe/rbe/rbe.htm>. Acesso em: 10 fev. 2010.

RIBEIRO, R. J. A percepção do Processo de Bolonha no Brasil. In: Ribeiro, R. J. et al. Políticas de reforma e internacionalização do ensino superior no Brasil e Alemanha. Seminário CAPES/DAAD. Revista Brasileira de Pós-graduação, v. 4, n. 8, p. 303-349, 2007. 
ROBERTSON S. L. O processo de Bolonha da Europa torna-se global: modelo, mercado, mobilidade, força intelectual ou estratégia para construção do Estado? Revista Brasileira de Educação: ANPEd, Rio de Janeiro, v. 14, n. 42, p. 407-422, set./dez. 2009.

SANTIAGO, R.; MAGALHÂES, A.; CARVALHO, T. O surgimento do managerialismo no sistema de ensino superior português. Coimbra: Fundação das Universidades Portuguesas e CIPES, 2005.

SGUISSARDI, V. A avaliação defensiva no "Modelo CAPES de Avaliação": é possível conciliar avaliação educativa com processos de regulação e controle do Estado? In: BIANCHETTI, L.; SGUISSARDI, V. (Org.). Dilemas da pós-graduação: gestão e avaliação. Campinas, SP: Autores Associados, 2009.

SGUISSARDI, V.; SILVA JUNIOR, J. dos R. Trabalho intensificado nas federais: pós-graduação e produtivismo acadêmico. São Paulo: Xamã, 2009.

SILVA JUNIOR, J. dos R. Racionalidade mercantil da pós-graduação: a produção da ciência pragmática e do individualismo profissional. In: QUARTIERO, E. M.; BIANCHETTI, L. (Org.). Educação corporativa: mundo do trabalho e do conhecimento: aproximaçóes. Santa Cruz do Sul: EDUNISC; São Paulo: Cortez, 2005.

SLAUGHTER, S; LESSLIE, L. L. Academic capitalism: politics, policies and the entrtepreneurial univesity. Baltimore: John Hopkins University Press, 1997.

SOARES, A. M. L.; PASSOS, J. D. (Org.). Teologia e ciência: diálogos acadêmicos em busca do saber. São Paulo: Paulinas; Educ, 2008.

UNIVERSIDADE DE SANTIAGO DE COMPOSTELA. Declaração de Compostela. Santiago de Compostela, 2004. Disponível em: <www. usc.es/gl/goberno/reitoria/iberoam.html>. Acesso em: 25 maio 2009.

VIDA RADICAL. Quanto vale a tradição. Disponível em: <vida-radical. planetaclix.pt/tradicao.htm>. Acesso em: 28 fev. 2011.

ZIMMERMANN, R. América Latina o não ser: uma abordagem filosófica a partir de Henrique Dussel (1962-1967). Petrópolis: Vozes, 1987. 


\section{Graduate studies in Iberoamerica. Temporalities conflict and confrontation. Tradition vs. Modernity}

\section{Abstract}

Research about evaluations conducted by CAPES, in Brazil, and the implementation of the Bologna Process in the European Union (EU), reveal two processes that have established paradigms of induced and accelerated changes in a short time. The development of research about graduate studies in Brazil and in some universities of the Iberian peninsula highlights a similar reality, although with differences in timing, depending on the space where the changes are taking place: the relation between tradition and modernity. It is in this context that the before, evoking tradition, and the now, pointing to (post) modernity, are materialized in a time in which past and present collide, often under a perspective that seems to annul the past and tradition as if ipso facto it is synonymous with something outdated that must be left behind, given that it is no longer operational in the mercantilist environment in the educational field. In this new era, under the CAPES Models and the Bologna Process, intellectuals are being challenged to preserve a field of praxis where the dialectic between tradition and modernity are not annulled. As public intellectuals they become reduced to institutionalized
Posgraduación en Iberoamerica. Conflicto de temporalidades y enfrentamientos. Tradicion vs. Modernidad

\section{Resumen}

La investigación sobre la evaluación realizada por la CAPES, en el Brasil, y la implementación del "Acuerdo de Bolonia", en la Unión Europea (UE), evidencia que estos dos procesos se constituyen en paradigmas de cambios inducidos, acelerados y en un reducido lapso de tiempo. Así mismo, el desarrollo de investigaciones sobre la pos graduación stricto sensu en el Brasil y en algunas universidades de la península ibérica evidencia una realidad similar, frente a la relación entre tradición y modernidad, aunque con desfases temporales, dependiendo del espacio donde están procesándose los cambios. En este contexto, el antes, evocando la tradición, y el ahora, representando la (pos)modernidad, se materializan en un tiempo en que pasado y presente se confrontan, muchas veces con la perspectiva de la anulación de un pasado, de una tradición, como si ipso facto fuesen sinónimo de anticuado, de algo que se tiene que dejar atrás, dado que no es más operacional para el mercantilismo imperante en el campo educativo. En esta nueva temporalidad, entre el "Modelo CAPES" y el "Proceso de Bolonia", los intelectuales se ven desafiados a preservar un campo 
intellectuals who must fulfill their tasks with no room for autonomy. This text is the fruit of post-doctoral research and presents and analyzes the basic elements in a comparative study between Brazil and the European Union.

Keywords: Traditional and modern education. Coordination of Improvement of Higher Education Personnel. Bologna Process. de praxis, donde la dialéctica entre tradición y modernidad no sea anulada, y donde ellos, en su condición de intelectuales públicos, no sean reducidos a intelectuales institucionalizados, cumplidores de funciones, sin espacio para el ejercicio de la autonomía. En este texto, resultado de la revisión para la investigación de pos doctorado, presento y analizo elementos básicos, del Estudio Comparado entre Brasil y la UE.

Palabras-clave: Educación Tradicional y Moderna. Coordinación de Perfeccionamiento de Personal de Educación Superior. Proceso de Bolonia.

\section{Lucídio Bianchetti}

Rua Elmo Kiseski, n. 80, apto. 201

Bairro Trindade

88036040 - Florianópolis, SC.

Telefones.: (48)3333-1024 (Res.); (48)3721-9246 (UFSC)

E-mail: lucidio.bianchetti@pq.cnpq.br

Recebido em: $2 / 12 / 2010$

Versão final recebida em: 22/10/2011

Aprovado em: 31/10/2011 